\title{
Self-Reported Social and Emotional Impact of Urinary Incontinence
}

\author{
Nancy H. Fultz, PhD, " and A. Regula Herzog, PhD*+
}

OBJECTIVE: Incontinence-specific and generic measures of well-being were regressed on potential predictors to identify incontinent respondents at risk for psychosocial distress and to understand the relationship between urinary incontinence (UI) and other determinants of social and emotional status.

DESIGN: Survey data were collected May 1994 through April 1996.

SETTING: Telephone interviews as a supplement to a nationally representative monthly consumer survey.

PARTICIPANTS: Analyses were based on 1,116 continent and 206 incontinent respondents age 40 and older.

MEASUREMENTS: Incontinent respondents self-reported the extent to which urine loss restricted social activities or affected their feelings about themselves. All respondents were asked whether they felt depressed, lonely, or sad. Covariates included sex, age, race, education, social desirability, health status, frequency of urine loss, quantity of loss, and urgency. RESULTS: The majority of incontinent respondents reported that urine loss did not restrict activities or diminish self-esteem. Incontinent respondents who were younger, male, less educated, lower in social desirability, in poorer health, or losing greater quantities of urine were more likely to report psychosocial distress, although these correlates were not consistently significant. Compared with continent respondents, significantly higher percentages of incontinent respondents reported feeling depressed, lonely, or sad. In the multivariate models, incontinence retained an independent association with loneliness, but not with sadness or depression.

CONCLUSION: Even though the direct psychosocial impact of urine loss may be minor in many cases, UI is associated with a constellation of physical and behavioral fac-

From the "Institute for Social Research and Institute of Gerontology, and Department of Psychology, University of Michigan, Ann Arbor, Michigan. Supported, in part, by Grant R01 DK47543 from the National Institute of Diabetes and Digestive and Kidney Diseases. An earlier version of these analyses was presented at the 49th Annual Scientific Meeting of The Gerontological Society of America, November 17-21, 1996, Washington, DC. Address correspondence to Nancy H. Fultz, PhD, Institute for Social Research, University of Michigan, 426 Thompson Street, PO Box 1248, Ann Arbor, MI 48106-1248. tors that can impose a social and emotional burden. This suggests that UI cannot be adequately evaluated or treated without consideration of the patient's overall quality of life. J Am Geriatr Soc 49:892-899, 2001.

Key words: urinary incontinence; subjective well-being; quality of life; survey

$\mathrm{N}$ umerous articles about urinary incontinence (UI) begin with references to the high prevalence and negative consequences of involuntary urine loss. Among these consequences, social isolation and psychological distress are often mentioned. Indeed, the potential for UI to diminish social and emotional well-being seems obvious. The empirical findings on this relationship are somewhat mixed, however. Although some studies have suggested that UI has a major impact on well-being, other studies conclude that the effect is more modest. ${ }^{1}$

A number of reviews of the relevant literature are available..$^{2-4}$ In a 1996 review, we speculated that variation in conclusions about the relationship between UI and wellbeing may result, in part, from the use of different analytic designs. ${ }^{5}$ One common strategy is to ask incontinent respondents to self-assess the social and emotional impact of urine loss. This is typically done by asking questions like, "Does fear of odor or smell restrict your activities?" 6 or "Do you find the urinary incontinence to be upsetting?" Another strategy, which is less widely used, compares continent and incontinent respondents on more global measures of subjective well-being, such as standard scales for depression or self-esteem. ${ }^{8}$ The distinction between these two approaches parallels the contrast between conditionspecific and generic health-related quality of life measures. Condition-specific measures tend to provide better discrimination within disease groups and to be more sensitive to change over time (because of greater content validity and relevance to patients), whereas generic measures are often more comprehensive in covering the multiple dimensions of health status and allow comparisons to be made across conditions or populations. ${ }^{9}$

Although there are exceptions, earlier studies that asked incontinent respondents to self-assess the social and 
emotional impact of UI suggested the more-negative outcomes, whereas studies that took the second approach suggested the more-moderate claims. Several factors could account for this pattern. First, the incontinent respondents questioned about the consequences of the condition might not have been representative of the larger population of incontinent people, thereby confounding the analytic design with sample differences. For example, patient samples could lead to an exaggerated assessment of the burden of UI because treatment-seeking is likely to be motivated by perceptions that the condition is problematic.

Second, without a comparison group, it is difficult to interpret the level of distress reported by the incontinent respondents. It is left to the researcher to decide whether a finding that $35 \%$ of incontinent people worry about accidental urine loss (for example) represents a major or a minor impact of UI on well-being. Third, respondents might not be able to make valid self-assessments about UI. By presenting UI as an appropriate reason for depression or social withdrawal, direct questioning may lead respondents to misattribute the cause of negative feelings and actions, thereby inflating the apparent effect of the condition. Related to this, epidemiological studies that compare continent and incontinent respondents typically measure physical and behavioral factors that might explain or account for a relationship between UI and psychosocial distress.

Two recent studies of UI included both condition-specific and generic measures of health-related quality of life. ${ }^{10,11}$ However, these findings were limited to clinical samples of incontinent persons. Aside from the survey reported here, we are not aware of a study of the adult U.S. population (middle-aged and older) that included both UIspecific measures of psychosocial impact and generic measures of depression, loneliness, and sadness. Designing such a study allowed us to evaluate the self-reported social and emotional consequences of UI on the basis of the two approaches. This article discusses the findings derived from each strategy.

\section{METHODS}

The data were collected through a supplement to the Survey of Consumer Attitudes (SCA) conducted at the Institute for Social Research, University of Michigan. The SCA is a nationally representative telephone survey of adults in the coterminous United States. Each month, a new Random Digit Dialing (RDD) cross-section of approximately 300 respondents is interviewed. (In addition, about 200 reinterviews are conducted each month with respondents from 6 months earlier.) All new RDD respondents age 40 and older were eligible for the supplement. The sample was accumulated across 12 months, May 1994 through April 1995, to provide enough cases for analysis. An additional year, May 1995 through April 1996, was devoted to interviewing an oversample of African-American respondents age 40 and older.

The supplement asked about general health, functional limitations, UI and other bladder and bowel symptoms, health behaviors, and social and emotional well-being. Continence status was determined through the question: "Other than the few drops right after urinating, have you involuntarily lost or leaked any amount of urine or been unable to hold your water and wet yourself during the past 6 months?" This question was preceded by an introduction that acknowledged the difficulty of reporting UI and stressed the need for accurate reporting: "The next questions may not be easy to talk about, but they are very important for research on health and aging. They are about the health condition called urinary incontinence. This occurs when people lose or leak urine involuntarily or cannot hold their water and wet themselves. Although some of these questions may seem personal, we need the most accurate information that you can give, and we appreciate your help in answering them." A follow-up question was also asked of respondents who answered "no" to the UI question: "Because this information is so important to research on health and aging, I want to be sure that you understand that we need to identify any urine loss, even a small amount or only on a very few days during the past 6 months: Have you involuntarily leaked or lost any urine at all, other than a few drops right after urinating?" These questions are similar to measures used in the Medical, Epidemiologic, and Social Aspects of Aging (MESA) study, ${ }^{12}$ which were shown to be valid and reliable. ${ }^{13}$

To gauge the social and emotional impact of UI, incontinent respondents were asked to self-report the extent of disturbance caused by the condition: "How much does losing urine restrict your social activities-would you say a lot, some, a little, or not at all?" "How much does losing urine affect your feelings about yourself-a lot, some, a little, or not at all?" These questions were chosen to represent one tradition of UI assessment. In addition, both continent and incontinent respondents were asked three general questions on subjective well-being: "Now I have a few questions about the past week and the feelings you have experienced. Please answer yes or no to the following questions. Did you feel depressed much of the time during the past week?" "Did you feel lonely much of the time during the past week?" "Did you feel sad much of the time?" These measures are based on widely used indicators of depressive symptoms and negative affect. ${ }^{14,15}$

Covariates for the following analyses were selected on the basis of findings from related studies. ${ }^{8,10}$ They represent basic demographic variables (sex, age, and race), education, social desirability response style, health status (functional limitations and self-assessed health), and characteristics of UI (frequency of loss, quantity of loss, and urgency symptoms).

The tendency to provide a socially desirable response was measured as the endorsement of zero through four items from Crowne and Marlowe. ${ }^{16}$ Functional impairment was measured as the number of activities of daily living (ADLs) with which the respondent reported difficulty. The ADLs included getting around the home, walking up and down a flight of stairs, dressing, undressing, getting in and out of bed, taking a bath or shower, getting to and using the toilet, and eating. This is a fairly standard set of tasks for ADL assessment. ${ }^{17}$ Self-assessed health was represented in the analyses as a dichotomous variable (excellent, very good, or good vs fair or poor).

Severity of UI included the self-reported frequency of urine loss, defined as the number of days of urine loss in a typical month, and the self-reported quantity of urine lost on each occasion; categories of the latter were collapsed for the analyses (few drops or a tablespoon vs quarter cup, 
Table 1. Predictor and Psychosocial Outcome Characteristics of the Sample by Continence Status

\begin{tabular}{|c|c|c|c|}
\hline & Continent $(\mathrm{N}=1,116)$ & Incontinent $(N=206)$ & Significance \\
\hline \multicolumn{4}{|l|}{ Predictors } \\
\hline \multicolumn{4}{|l|}{ Sex } \\
\hline Female (\%) & 48.60 & 79.18 & \\
\hline Male (\%) & 51.40 & 20.82 & $\chi^{2}=65.26, d f=1, P<.001$ \\
\hline \multicolumn{4}{|l|}{ Age $(40-95)$} \\
\hline Mean & 56.56 & 59.87 & $F=12.08, d f=1, P<.001$ \\
\hline \multicolumn{4}{|l|}{ Race } \\
\hline African American (\%) & 6.37 & 6.93 & \\
\hline Caucasian (\%) & 93.63 & 93.07 & $\chi^{2}=.09, d f=1, P>.10$ \\
\hline \multicolumn{4}{|l|}{ Education (0-17) } \\
\hline Mean & 13.58 & 13.17 & $F=4.36, d f=1, P<.05$ \\
\hline \multicolumn{4}{|l|}{ Social desirability (0-4) } \\
\hline Mean & 2.80 & 2.78 & $F=0.09, d f=1, P>.10$ \\
\hline \multicolumn{4}{|l|}{ Functional impairment (0-8) } \\
\hline Mean & 0.34 & 0.96 & $F=42.73, d f=1, P<.001$ \\
\hline \multicolumn{4}{|l|}{ Self-assessed health } \\
\hline Excellent, very good, good (\%) & 84.74 & 73.69 & \\
\hline Fair, poor (\%) & 15.26 & 26.31 & $\chi^{2}=15.06, d f=1, P<.001$ \\
\hline \multicolumn{4}{|l|}{ Frequency of urine loss $(0-31)$} \\
\hline Mean & $N / A$ & 8.75 & $\mathrm{~N} / \mathrm{A}$ \\
\hline \multicolumn{4}{|l|}{ Quantity of urine loss } \\
\hline A tablespoon or less (\%) & $\mathrm{N} / \mathrm{A}$ & 84.65 & $\mathrm{~N} / \mathrm{A}$ \\
\hline More than a tablespoon (\%) & & 15.35 & \\
\hline \multicolumn{4}{|l|}{ Type of incontinence } \\
\hline Any urgency (\%) & N/A & 75.0 & $\mathrm{~N} / \mathrm{A}$ \\
\hline No urgency (\%) & & 25.0 & \\
\hline \multirow{2}{*}{\multicolumn{4}{|c|}{$\begin{array}{l}\text { Psychosocial outcomes } \\
\text { Incontinence restricts activities }\end{array}$}} \\
\hline \multicolumn{2}{|l|}{ Incontinence restricts activities } & & \\
\hline Not at all (\%) & $\mathrm{N} / \mathrm{A}$ & 81.48 & $\mathrm{~N} / \mathrm{A}$ \\
\hline A little* (\%) & & 8.41 & \\
\hline Some* $(\%)$ & & 2.78 & \\
\hline A lot* $(\%)$ & & 7.33 & \\
\hline \multicolumn{4}{|c|}{ Incontinence affects feelings about self } \\
\hline Not at all & N/A & 61.95 & $\mathrm{~N} / \mathrm{A}$ \\
\hline A little ${ }^{\dagger}(\%)$ & & 15.94 & \\
\hline Some $^{\dagger}(\%)$ & & 11.83 & \\
\hline$A \operatorname{lot}^{\dagger}(\%)$ & & 10.29 & \\
\hline \multicolumn{4}{|l|}{ Depression } \\
\hline Yes (\%) & 14.37 & 20.59 & \\
\hline No $(\%)$ & 85.63 & 79.41 & $\chi^{2}=5.18, d f=1, P<.05$ \\
\hline \multicolumn{4}{|l|}{ Loneliness } \\
\hline Yes (\%) & 9.57 & 23.15 & \\
\hline No $(\%)$ & 90.43 & 76.85 & $\chi^{2}=31.06, d f=1, P<.001$ \\
\hline \multicolumn{4}{|l|}{ Sadness } \\
\hline Yes (\%) & 12.37 & 19.65 & \\
\hline No (\%) & 87.63 & 80.35 & $\chi^{2}=7.88 . d f=1, P<.01$ \\
\hline
\end{tabular}

${ }^{*}$ These categories were collapsed for subsequent analyses.

${ }^{+}$These categories were collapsed for subsequent analyses.

half cup, one cup, or more). Type of UI was defined as urge and mixed versus pure stress and other types. This was determined by respondents' reports of the activities and circumstances leading to urine loss (see the Appendix for question wordings and the classification scheme). We chose to contrast urgency symptoms with all others (rather than to differentiate stress, urge, mixed, and other UI) because of findings from prior research. ${ }^{18,19}$ Moreover, exploratory analyses of the data structure suggested that the urgency items represented a common dimension; the other items did not form interpretable groupings to the same extent.

Age, education, social desirability, functional impairment, self-assessed health, frequency of UI, and quantity of urine loss were coded so that a higher value indicated more of the characteristic being measured. Sex was coded 1 for female and 0 for male, race was coded 1 for African American and 0 for Caucasian, and type of UI was coded 1 if any symptoms of urgency were reported and 0 if no 
urgency symptoms were reported. The UI-specific outcomes were dichotomized to compare any social or emotional impact of UI (coded 1) with no impact (coded 0$)$.

One thousand four hundred and ninety-six respondents completed the standard version of the supplement. A shorter experimental version, which omitted the UI introduction and follow-up, was administered to an additional 236 respondents. ${ }^{20}$ The response rate for the total sample was $58 \%$. The data were weighted to adjust for the purposeful overrepresentation of African-American respondents and to correct for possible sources of bias such as differential probabilities of selection at the household level, nonresponse, and departures of sample distributions from the underlying distribution, which are inherent in the sampling process. Theoretically, weighting the data improves our ability to generalize findings from the sample to the population. Empirically, our investigations suggest that results from the weighted and unweighted data are not dramatically different.

The following analyses are based on the 1,116 continent and 206 incontinent African-American and Caucasian respondents who received the standard version of the questionnaire and had complete data for all of the variables in the models. The basic analytical strategy was to regress the outcome variables on each of the potential predictors individually and then to build multivariate models from those that had $P$-values less than .25 in the univariate tests. ${ }^{21}$ The regressions were run using PROC LOGISTIC in SAS 6.12 for Windows.

\section{RESULTS}

Table 1 describes the sample in terms of predictor and outcome characteristics by continence status. Consistent with previous findings, the incontinent respondents were more likely to be female, older, more functionally impaired, and in poorer self-reported health than their continent counterparts. The incontinent respondents also reported slightly less education. No significant differences between continent and incontinent respondents were found for race or social desirability.

Results for the two UI-specific outcome measures indicate that this condition had a negative impact on some respondents' well-being, but that the majority were not affected. Eighty-one percent of the respondents said that UI did not restrict their social activities at all, compared with about $7 \%$ who said that it restricted their social activities a lot. UI appears to have had somewhat more impact on respondents' emotional status. About $62 \%$ reported no impact, whereas about $10 \%$ reported that UI affected their feelings about themselves a lot. The two dimensions are related, but not redundant; there is a moderately strong positive association between UI restricting social activities and UI affecting feelings about oneself $(r=.43, p<.001)$.

Interestingly, the impact of UI appears to be greater when psychosocial well-being is assessed through the global measures. The proportions of continent and incontinent respondents reporting depression, loneliness, and sadness are significantly different, with the incontinent respondents experiencing more distress. As might be expected, the three global measures are moderately interrelated and form a separate cluster from the two UI-specific measures (data not shown).

Table 2 provides odds ratios and $95 \%$ confidence intervals for pairings of predictors and outcomes for incontinent respondents only. The broad dimensions of demographic characteristics, reporting style, health, and severity/ type of UI appear to be important determinants of social and emotional well-being; race is the only variable that is not related to at least one of the outcomes, at $P<.25$. However, the variables to be included in the multivariate models vary across the outcomes. There is not a consistent set of predictors for either the UI-specific measures or the global measures.

The results of the multivariate models are shown in Table 3. Male respondents and respondents who lost more than a tablespoon of urine at a time reported being more socially restricted by UI. This pattern is repeated for the impact of UI on feelings about oneself, although neither variable reaches statistical significance. The only significant predictor of that outcome is social desirability, with respondents who scored higher on social desirability reporting less impact of UI. Younger age, lower education, and poorer self-assessed health appear to be risk factors for depression. Lower education and higher quantities of

Table 2. Logistic Regression of Psychosocial Outcome Variables on Individual Predictors, Incontinent Respondents Only $(\mathrm{N}=206)$

\begin{tabular}{llllll}
\hline \multicolumn{1}{c}{ Predictors } & $\begin{array}{c}\text { Restricts Activities } \\
\text { OR }(95 \% \mathrm{Cl})\end{array}$ & $\begin{array}{c}\text { Affects Feelings } \\
\text { OR }(95 \% \mathrm{Cl})\end{array}$ & $\begin{array}{c}\text { Depression } \\
\text { OR }(95 \% \mathrm{Cl})\end{array}$ & $\begin{array}{c}\text { Loneliness } \\
\text { OR }(95 \% \mathrm{Cl})\end{array}$ & $\begin{array}{c}\text { Sadness } \\
\text { OR }(95 \% \mathrm{Cl})\end{array}$ \\
\hline Sex & $0.44(0.20-0.97)^{\star}$ & $0.65(0.33-1.28)^{\star}$ & $1.51(0.64-4.02)$ & $1.02(0.47-2.36)$ & $0.92(0.41-2.23)$ \\
Age & $1.03(1.00-1.06)^{\star}$ & $1.01(0.99-1.03)$ & $0.95(0.92-0.98)^{\star}$ & $0.99(0.97-1.02)$ & $0.97(0.94-0.99)^{\star}$ \\
Race & $1.94(0.52-6.09)$ & $0.53(0.13-1.67)$ & $1.38(0.35-4.41)$ & $1.34(0.36-4.19)$ & $1.07(0.23-3.63)$ \\
Education & $0.78(0.67-0.90)^{\star}$ & $0.92(0.82-1.03)^{\star}$ & $0.80(0.69-0.91)^{\star}$ & $0.84(0.73-0.95)^{\star}$ & $0.80(0.69-0.92)^{\star}$ \\
Social desirability & $1.10(0.80-1.56)$ & $0.79(0.61-1.02)^{\star}$ & $0.98(0.72-1.35)$ & $0.89(0.66-1.20)$ & $0.71(0.52-0.97)^{\star}$ \\
Functional impairment & $1.39(1.17-1.66)^{\star}$ & $1.19(1.02-1.41)^{\star}$ & $1.18(1.00-1.40)^{\star}$ & $1.15(0.97-1.35)^{\star}$ & $1.21(1.02-1.44)^{\star}$ \\
Self-assessed health & $0.29(0.14-0.61)^{\star}$ & $0.47(0.25-0.89)^{\star}$ & $0.33(0.16-0.68)^{\star}$ & $0.54(0.27-1.09)^{\star}$ & $0.31(0.15-0.64)^{\star}$ \\
Frequency of loss & $1.06(1.02-1.09)^{\star}$ & $1.04(1.01-1.06)^{\star}$ & $1.03(1.00-1.06)^{\star}$ & $1.01(0.98-1.04)$ & $1.03(1.00-1.06)^{\star}$ \\
Quantity of loss & $4.12(1.79-9.40)^{\star}$ & $1.59(0.74-3.43)^{\star}$ & $2.04(0.85-4.64)^{\star}$ & $2.92(1.30-6.48)^{\star}$ & $1.63(0.65-3.81)$ \\
Urgency symptoms & $3.22(1.22-10.96)^{\star}$ & $1.81(0.93-3.69)^{\star}$ & $1.81(0.79-4.65)^{\star}$ & $2.10(0.94-5.32)^{\star}$ & $2.67(1.08-8.01)^{\star}$ \\
\hline
\end{tabular}

Note: Entries are odds ratios (OR) with $95 \%$ confidence intervals (CI).

${ }^{*} P<.25$. 
Table 3. Logistic Regression of Psychosocial Outcome Variables on Multiple Predictors, Incontinent Respondents Only $(\mathrm{N}=206)$

\begin{tabular}{|c|c|c|c|c|c|}
\hline Predictors & $\begin{array}{l}\text { Restricts Activities } \\
\text { OR }(95 \% \mathrm{Cl})\end{array}$ & $\begin{array}{l}\text { Affects Feelings } \\
\text { OR }(95 \% \mathrm{Cl})\end{array}$ & $\begin{array}{l}\text { Depression } \\
\text { OR }(95 \% \mathrm{Cl})\end{array}$ & $\begin{array}{l}\text { Loneliness } \\
\text { OR }(95 \% \mathrm{Cl})\end{array}$ & $\begin{array}{c}\text { Sadness } \\
\text { OR }(95 \% \mathrm{Cl})\end{array}$ \\
\hline Sex & $0.31(0.12-0.81)^{\dagger}$ & $0.55(0.26-1.16)$ & * & * & * \\
\hline Age & 1.02 (0.99-1.05) & * & $0.93(0.90-0.96)^{\dagger}$ & * & $0.96(0.92-0.99)^{\dagger}$ \\
\hline Education & $0.85(0.72-1.00)$ & $0.94(0.82-1.06)$ & $0.78(0.67-0.93)^{\dagger}$ & $0.87(0.75-0.99)^{\dagger}$ & $0.78(0.66-0.91)^{\dagger}$ \\
\hline Social desirability & * & $0.74(0.56-0.98)^{\dagger}$ & * & * & $0.68(0.46-0.99)^{\dagger}$ \\
\hline Functional impairment & $1.17(0.94-1.47)$ & $1.05(0.87-1.28)$ & $0.97(0.78-1.19)$ & $1.04(0.85-1.26)$ & $1.01(0.81-1.25)$ \\
\hline Self-assessed health & $0.68(0.27-1.79)$ & $0.71(0.34-1.50)$ & $0.38(0.16-0.89)^{\dagger}$ & $0.75(0.34-1.71)$ & $0.40(0.17-0.94)^{\dagger}$ \\
\hline Frequency of loss & $1.04(1.00-1.08)$ & $1.03(1.00-1.06)$ & $1.01(0.97-1.04)$ & * & $1.01(0.97-1.04)$ \\
\hline Quantity of loss & $3.47(1.31-9.28)^{\dagger}$ & $1.43(0.62-3.25)$ & $2.04(0.74-5.43)$ & $2.32(0.99-5.35)^{\dagger}$ & * \\
\hline Urgency symptoms & $1.62(0.50-6.23)$ & $1.28(0.62-2.75)$ & $1.90(0.72-5.54)$ & $1.58(0.67-4.12)$ & $2.63(0.92-8.85)$ \\
\hline
\end{tabular}

Note: Entries are odds ratios (OR) with $95 \%$ confidence intervals (CI).

${ }^{\star}$ Variable was not included in the final model.

${ }^{+} P<.05$.

urine loss predict loneliness. The findings for sadness are similar to those for depression, with the addition that respondents who scored higher on social desirability reported less sadness.

Table 4 parallels Table 2, but for the entire sample. Here, the presence of UI replaces severity and type on the list of potential risks for depression, loneliness, and sadness. With the larger sample size, only two coefficients had $P$-values greater than .25 ; age was eliminated from the model for depression and race was omitted from the model for sadness.

The resulting multivariate models are presented in $\mathrm{Ta}$ ble 5 . Depression, loneliness, and sadness are all more likely among female respondents, respondents who score lower on social desirability, and less-healthy respondents. Depression and loneliness are also predicted by lower education. Once these variables are controlled, UI is significantly related to loneliness, but not to depression or sadness.

\section{DISCUSSION}

Similar to the literature that gave rise to this study, pieces of our findings could be used to support a range of conclusions about the impact of UI on psychosocial outcomes. When incontinent respondents self-assessed the extent to which urine loss restricted social activities or affected their feelings about themselves, the majority reported no adverse consequences. However, a sizable minority indicated that UI negatively affected their social and emotional well-being. Moreover, the incontinent respondents reported being lonelier, sadder, and more depressed than the continent respondents. When additional variables were controlled only loneliness remained significantly associated with UI.

Rather than picking among these findings for evidence that $\mathrm{UI}$ is or is not a debilitating condition, we believe that it is necessary to consider the results as a whole. Doing so moves us beyond broad generalizations about the implications of UI toward a better specification of the factors that contribute to or diminish quality of life. Two important aspects of this task are: (1) to identify those incontinent respondents who are at risk for psychosocial distress and (2) to understand the relationship between UI and other determinants of social and emotional state.

Regarding the first of these issues, Table 3 shows that incontinent respondents who are younger, male, less educated, lower on social desirability, in poorer self-reported health, or losing greater quantities of urine are more likely to report psychosocial distress. Although these variables are not consistently significant across the outcomes, they do appear to be reasonable predictors. That is, these variables relate to the outcomes in ways that "make sense"

Table 4. Logistic Regression of Psychosocial Outcome Variables on Individual Predictors, All Respondents $(\mathrm{N}=1,322)$

\begin{tabular}{|c|c|c|c|}
\hline Predictors & $\begin{array}{l}\text { Depression } \\
\text { OR }(95 \% \mathrm{Cl})\end{array}$ & $\begin{array}{l}\text { Loneliness } \\
\text { OR (95\% Cl) }\end{array}$ & $\begin{array}{c}\text { Sadness } \\
\text { OR (95\% Cl) }\end{array}$ \\
\hline Sex & $1.50(1.10-2.04)^{*}$ & $1.87(1.32-2.68)^{*}$ & $2.12(1.52-2.99)^{\star}$ \\
\hline Age & $1.00(0.99-1.02)$ & $1.02(1.00-1.03)^{*}$ & $1.02(1.00-1.03)^{\star}$ \\
\hline Race & $1.46(0.82-2.48)^{*}$ & $1.66(0.90-2.91)^{*}$ & $1.32(0.71-2.32)$ \\
\hline Education & $0.87(0.82-0.92)^{*}$ & $0.84(0.79-0.90)^{*}$ & $0.92(0.86-0.97)^{*}$ \\
\hline Social desirability & $0.81(0.71-0.92)^{*}$ & $0.86(0.74-1.00)^{*}$ & $0.90(0.79-1.04)^{\star}$ \\
\hline Functional impairment & $1.26(1.14-1.38)^{*}$ & $1.27(1.15-1.40)^{*}$ & $1.27(1.16-1.39)^{\star}$ \\
\hline Self-assessed health & $0.37(0.26-0.52)^{*}$ & $0.36(0.25-0.53)^{*}$ & $0.44(0.31-0.64)^{\star}$ \\
\hline Incontinence & $1.55(1.05-2.24)^{*}$ & $2.85(1.93-4.15)^{*}$ & $1.73(1.16-2.53)^{\star}$ \\
\hline
\end{tabular}

Note: Entries are odds ratios (OR) with $95 \%$ confidence intervals (CI).

${ }^{\star} P<.25$. 


\begin{tabular}{lccc}
\hline \multicolumn{2}{l}{ Table 5. Logistic Regression of Psychosocial Outcome Variables on Multiple Predictors, All Respondents $(\mathbf{N}=1,322)$} \\
\hline \multicolumn{1}{c}{ Predictors } & $\begin{array}{c}\text { Depression } \\
\text { OR }(95 \% \text { Cl) }\end{array}$ & $\begin{array}{c}\text { Loneliness } \\
\text { OR }(95 \% \text { Cl) }\end{array}$ & OR $(95 \%$ Cl) \\
\hline Sex & $1.42(1.03-1.97)^{\dagger}$ & $1.52(1.05-2.23)^{\dagger}$ & $1.99(1.41-2.85)^{\dagger}$ \\
Age & $*$ & $1.01(1.00-1.03)$ & $1.01(1.00-1.03)^{\dagger}$ \\
Race & $1.26(0.69-2.21)$ & $1.42(0.73-2.62)$ & $*$ \\
Education & $0.89(0.84-0.95)^{\dagger}$ & $0.88(0.82-0.94)^{\dagger}$ & $0.96(0.90-1.03)$ \\
Social desirability & $0.76(0.66-0.87)^{\dagger}$ & $0.76(0.65-0.90)^{\dagger}$ & $0.83(0.71-0.97)^{\dagger}$ \\
Functional impairment & $1.15(1.04-1.28)^{\dagger}$ & $1.14(1.01-1.27)^{\dagger}$ & $1.19(1.07-1.32)^{\dagger}$ \\
Self-assessed health & $0.53(0.36-0.79)^{\dagger}$ & $0.60(0.39-0.94)^{\dagger}$ & $0.62(0.41-0.96)^{\dagger}$ \\
Incontinence & $1.12(0.74-1.68)$ & $2.10(1.38-3.16)^{\dagger}$ & $1.15(0.75-1.73)$ \\
\hline
\end{tabular}

Note: Entries are odds ratios (OR) with $95 \%$ confidence intervals (CI).

${ }^{*}$ Variable was not included in the final model.

${ }^{\dagger} P<.05$.

(demonstrating a type of validity), given the conceptual and empirical literature on UI.

Prior work suggests that the impact of UI is more negative for younger adults than for older adults. ${ }^{10,22,23}$ Involuntary urine loss is commonly attributed to aging and is likely to be perceived as a normal condition for older adults. ${ }^{24} \mathrm{~A}$ condition that is considered normal is less likely to be socially or emotionally damaging than is one that is viewed as deviant. Moreover, to the extent that younger and older adults have different lifestyle preferences and obligations, there may be varying degrees of adaptation to the condition.

A similar argument could be made for our finding that incontinent men, compared with incontinent women, reported more restrictions on social activities. UI is commonly associated with pregnancy and childbirth, such that it may be viewed as a normal part of being female. ${ }^{24}$ Moreover, women's experience with managing menstrual bleeding could be extended to managing urine loss, furthering the processes of normalization and adaptation..$^{25}$ Interestingly, two earlier studies did not find an association between respondents' sex and the psychosocial impact of UI. ${ }^{7,10}$ More research on the relationship between gender and the psychosocial impact of UI is needed because the majority of previous studies excluded men.

Respondents' education appears to be an important variable in epidemiological research on UI. Burgio et al. found a relationship between education and UI which suggested that more educated respondents may be more likely to recognize and acknowledge the condition. ${ }^{26}$ Similar results were found by Fultz et al..$^{27}$ More generally, the misreporting of chronic conditions has been shown to vary by respondents' educational attainment, with less-educated respondents tending to underreport. ${ }^{28}$ Furthermore, education is an important predictor of socioeconomic status and of cognitive functioning. Respondents who lack the financial or cognitive resources to successfully manage their urine loss are likely to find it more disruptive. This is consistent with our finding that the less-educated incontinent respondents reported more depression, loneliness, and sadness than did the more highly educated incontinent respondents.

Severe urine loss appears to have greater social and emotional consequences than does mild loss. This corre- sponds with findings from earlier studies, ${ }^{18,22,29}$ although the relationship between objective indicators of severity and perceived impact is known to be imperfect. ${ }^{3,30}$ Moreover, in keeping with results from a recent survey in Spain, ${ }^{31}$ we found that the volume of urine loss may be a more important determinant than the frequency of loss.

Using these data, we did not find the relationship between type of UI and psychosocial impact that others have shown. 18,19,23,29,32 Our classification scheme (urgency symptoms vs all others) did not group respondents into the standard categories for type of UI (stress, urge, mixed, other), which was a limitation of this study. In addition, the choice of a different instrument to measure the impact of UI (e.g., the Incontinence Impact Questionnaire ${ }^{33}$ ) might have produced more-consistent results on this point (and yielded different conclusions, more generally). It is also possible that results from these analyses would have differed had we specified a longer time frame for the retrospective self-reports of sadness, loneliness, and depression.

Regarding the relationship between UI and other determinants of social and emotional state, our findings are somewhat mixed. The odds ratio for UI as a predictor of loneliness remained significant in the multivariate model but decreased from 2.85 (Table 4) to 2.10 (Table 5). For sadness and depression, controlling demographic characteristics, education, reporting style, and health status reduced the odds ratios for UI from 1.55 and 1.73 to a nonsignificant 1.12 and 1.15 , respectively (Tables 4 and 5). This suggests that much of the apparent effect of UI on psychosocial outcomes may be attributable to the other variables in the multivariate models, with which UI is correlated. Additional variation might have been explained had we also measured specific comorbid conditions. To do so, however, would have placed too great a response burden on the SCA participants.

Comparable results were found in earlier surveys. Data from the MESA study showed that UI, particularly severe UI, was weakly related to depression, negative affect, and low life satisfaction. Those relationships were partly explained by the fact that the incontinent respondents were less healthy than the continent respondents. ${ }^{8}$ Using data from the East Boston component of the Established Populations for Epidemiologic Study of the Elderly (EPESE), Wetle et al. ${ }^{34}$ reported that difficulty holding 
urine "all of the time" or "most of the time" was strongly associated with experiencing four or more symptoms from the 10-item version of the Center for Epidemiologic Studies-Depression scale. Again, the relationship diminished considerably in multivariate models that included other health and behavioral conditions. Dugan et al. ${ }^{35}$ found clear evidence that UI is related to depressive symptoms in older adults, but they noted, "Depressive symptoms appeared to be influenced by gender and physical health to a greater degree than UI."

Interestingly, a survey of participants in the University of Pittsburgh Healthy Women Study found that UI related to only one out of 12 measures of self-consciousness, social anxiety, trait anxiety, self-esteem, depression, tension, or anger. ${ }^{36}$ Participants were screened to exclude women with hypertension and those taking medications for many common chronic conditions. That health status was already controlled in this study may explain why bivariate relationships between UI and social and emotional wellbeing were not evident.

Our expectation that the UI-specific measures, compared with the global measures, would suggest that the greater impact of UI was not upheld. Moreover, taken together, our findings do not support the hypothesis that UI has a major independent effect on social or emotional status. This does not mean that UI is inconsequential for everyone who experiences it. Using either approach to assessing the psychosocial impact of UI, there is evidence that-for some individuals-involuntary urine loss can be debilitating. This is consistent with findings that interventions for UI can improve patients' well-being. ${ }^{11,29}$

What we wish to stress is that a focus on UI, in isolation from comorbid conditions, may be shortsighted. UI is associated with a constellation of physical and behavioral factors that can impose a social and emotional burden. Even though the direct impact of urine loss may be minor in many cases, patients' reports of UI should alert clinicians to the importance of considering the totality of the patients' quality of life.

\section{REFERENCES}

1. Wyman JF. The psychiatric and emotional impact of female pelvic floor dysfunction. Curr Opin Obstet Gynecol 1994;6:336-339.

2. Herzog AR, Diokno AC, Fultz NH. Urinary incontinence: Medical and psychosocial aspects. Annu Rev Gerontol Geriatr 1989;9:74-119.

3. Naughton MJ, Wyman JF. Quality of life in geriatric patients with lower urinary tract dysfunction. Am J Med Sci 1997;314:219-227.

4. Wyman JF, Harkins SW, Fantl JA. Psychosocial impact of urinary incontinence in the community-dwelling population. J Am Geriatr Soc 1990;38: 282-288.

5. Fultz NH, Herzog AR. Epidemiology of urinary symptoms in the geriatric population. Urol Clin North Am 1996;23:1-10.

6. Norton C. The effects of urinary incontinence in women. Int Rehab Med 1982;4:9-14.

7. Ouslander JG, Abelson S. Perceptions of urinary incontinence among elderly outpatients. Gerontologist 1990;30:369-372.

8. Herzog AR, Fultz, NH, Brock BM et al. Urinary incontinence and psychological distress among older adults. Psychol Aging 1988;3:115-121.
9. Patrick DL, Deyo RA. Generic and disease-specific measures in assessing health status and quality of life. Med Care 1989;27:S217-S232

10. Dugan E, Cohen S, Robinson D et al. The quality of life of older adults with urinary incontinence: Determining generic and condition-specific predictors. Qual Life Res 1998;7:337-344.

11. Wyman JF, Fantl JA, McClish DK et al. Quality of life following bladder training in older women with urinary incontinence. Int Urogynecol J 1997;8: 223-229.

12. Diokno AC, Brock BM, Brown MB et al. Prevalence of urinary incontinence and other urological symptoms in the non-institutionalized elderly. J Urol 1986;136:1022-1025.

13. Herzog AR, Fultz NH. Prevalence and incidence of urinary incontinence in community-dwelling populations. J Am Geriatr Soc 1990;38:273-281.

14. Bradburn NM. The Structure of Psychological Well-Being. Chicago: Aldine, 1969.

15. Radloff LS. The CES-D scale: A self-report depression scale for research in the general population. Appl Psychol Meas 1977;1:385-401.

16. Crowne D, Marlowe D. The Approval Motive. New York: Wiley, 1964.

17. Rodgers W, Miller B. A comparative analysis of ADL questions in surveys of older people. J Gerontol B Psychol Sci Soc Sci 1997;52B:21-36.

18. Lagro-Janssen T, Smits A, van Weel C. Urinary incontinence in women and the effects on their lives. Scand J Prim Health Care 1992;10:211-216.

19. Grimby A, Milsom I, Molander U et al. The influence of urinary incontinence on the quality of life of elderly women. Age Ageing 1993;22:82-89.

20. Fultz NH, Herzog AR. Prevalence of urinary incontinence in middle-aged and older women: A survey-based methodological experiment. J Aging Health 2000;12:459-469.

21. Hosmer DW, Lemeshow S. Applied Logistic Regression. New York: John Wiley and Sons, 1989.

22. Hunskaar S, Sandvik H. One hundred and fifty men with urinary incontinence: III. Psychosocial consequences. Scand J Health Care 1993;11:193-196.

23. Hunskaar S, Vinsnes A. The quality of life in women with urinary incontinence as measured by the Sickness Impact Profile. J Am Geriatr Soc 1991;39: 378-382.

24. Umlauf MG, Goode PS, Burgio KL. Psychosocial issues in geriatric urology. Urol Clin North Am 1996;23:127-136.

25. Fultz NH, Herzog AR. Measuring urinary incontinence in surveys. Gerontologist 1993;33:708-713.

26. Burgio KL, Locher JL, Zyczynski H et al. Urinary incontinence during pregnancy in a racially mixed sample: Characteristics and predisposing factors. Int Urogynecol J 1996;7:69-73.

27. Fultz NH, Herzog AR, Raghunathan TE et al. Prevalence and severity of urinary incontinence in older African American and Caucasian women. J Gerontol A Biol Sci Med Sci 1999;54A:M299-M303.

28. Mackenbach JP, Looman CW, van der Meer JBW. Differences in the misreporting of chronic conditions, by level of education: The effect on inequalities in prevalence rates. Am J Public Health 1996;86:706-711.

29. Seim A, Hermstad R, Hunskaar S. Management in general practice significantly reduced psychosocial consequences of female urinary incontinence. Qual Life Res 1997;6:257-264.

30. Wyman JF, Harkins SW, Choi SC et al. Psychosocial impact of urinary incontinence in women. Obstet Gynecol 1987;70:378-381.

31. Gavira Iglesias FJ, Caridad y Ocerin JM, Perez del Molino Martin J et al. Prevalence and psychosocial impact of urinary incontinence in older people of a Spanish population. J Gerontol A Biol Sci Med Sci 2000;55A:M207-M214.

32. Sandvik H, Kveine E, Hunskaar S. Female urinary incontinence: Psychosocial impact, self care, and consultations. Scand J Caring Sci 1993;7:53-56.

33. Shumaker SA, Wyman JF, Uebersax JS et al. for the Continence Program in Women (CPW) Research Group. Health-related quality of life measures for women with urinary incontinence: The Incontinence Impact Questionnaire and the Urogenital Distress Inventory. Qual Life Res 1994;3:291-306.

34. Wetle T, Scherr P, Branch LG et al. Difficulty with holding urine among older persons in a geographically defined community: Prevalence and correlates. J Am Geriatr Soc 1995;43:349-355.

35. Dugan E, Cohen SJ, Bland DR et al. The association of depressive symptoms and urinary incontinence among older adults. J Am Geriatr Soc 2000;48: 413-416.

36. Burgio KL, Matthews, KA, Engel, BT. Prevalence, incidence and correlates of urinary incontinence in healthy, middle-aged women. J Urol 1991;146:12551259. 
APPENDIX

Urinary Symptoms Typology and Response Frequencies

Next l'll read you a list of things that some people say can cause them to lose urine beyond their control and wet themselves. Tell me whether each one has caused you to lose urine in the past 6 months.

Coughing hard?

Yes (\%)

No (\%)

Sneezing?

Lifting heavy things?

Bending over?

Vomiting?

Straining to do something like opening a jar or pulling a heavy object?

Laughing?

Walking briskly or jogging?

Straining if constipated?

Suddenly having the feeling that your bladder is very full?*

Getting up from a bed or chair?

Hearing or feeling running water?*

Suddenly finding that you are losing or about to lose urine with very little warning?*

Arriving at your door or putting your key in the lock?*

Not being able to wait at least 5 minutes until it is convenient to go to the toilet?*
56.1

51.4

19.6

9.4

14.7

13.3

39.4

18.4

21.7

55.7

23.9

26.5

44.6

30.2

38.8
43.9

48.6

80.4

90.6

85.3

86.7

60.6

81.6

78.3

44.3

76.1

73.5

55.4

69.8

61.2

Note: $\mathrm{N}=206$. Questions were asked of incontinent respondents only.

*Answering "Yes" is an indicator of urgency. 